\title{
Mühendisliğin STEM Eğitimine Entegrasyonunda Kuramsal Bir İnceleme
}

\section{A Theoretical Review of Engineering Integration in STEM Education}

\begin{tabular}{l} 
Makale Hakkında \\
\hline Gönd. Tarihi: 19.12.2020 \\
Kabul Tarihi: 01.10.2021 \\
Yayın Tarihi: 01.11.2021 \\
Anahtar Kelimeler \\
STEM eğitimi, \\
Mühendislik, \\
Mühendislik \\
entegrasyonu, \\
Mühendislik tasarım \\
süreci.
\end{tabular}

\section{Makale Hakkında}

01.10 .2021

\section{Özet}

STEM eğitimi, farkl disiplinlerin bütünleştirilerek ögrretimini konu alır. Bu bakış açısındaki temel düşünce, gerçek yaşamda STEM kavram ve becerilerinin bütünsel olarak bulunmasına karşın bunların okul derslerinde birbirinden ayr olarak kazandırılmaya çalışılmasıdır. STEM eğitiminin öncelikli hedefleri arasında yer alan 21. yüzyll yeterliklerinin ögrencilere kazandırlmasl ve bu yeterliklerin transfer edilebilirliğinin desteklenmesi açısından mühendislik özel bir öneme sahiptir. Mühendislik, problem çözme odaklı bir yapıya sahip olma, mühendislik tasarımı ile etkili öğretim yöntemlerinin uygulanmasina olanak să̆lama ve ögrencilerin kendi deneyimleri ile öğrenmeleri için ögrenme ortamı oluşturma gibi özel nitelikleri bünyesinde barındırır. Ancak, bu noktada karşılaşılan temel sorun STEM eğitiminde etkili bir mühendislik entegrasyonunun nasıl gerçekleştirileceğidir. Bu bağlamda, araştırmanın amacı STEM eğitimi bakış açısı ile alanyazın incelemesi temelinde mühendisliğin doğasını ortaya koymak ve STEM eğitiminde etkili bir mühendislik entegrasyonunun nasıl gerçekleştirileceğini kuramsal olarak incelemektir. Araştırma sonuçları mühendisliğin STEM eğitimine entegrasyonunda en kabul gören yaklaşımın ögrenme ortamlarına mühendislik tasarımının aktarılması olduğunu ortaya koymuştur. Ayrıca araştırma sonuçlarl, ögretim süreçlerinde mühendislikle ilgili temel kavram, beceri ve uygulamalara vurgu yapılmasinın entegrasyonun niteliğini artırabileceğini ve bu tür bir entegrasyonun Türkiye bă̆lamında ögrenme çıtılırını destekleyebileceğini göstermiştir.
\end{abstract}

Hasan Zühtü OKULU ${ }^{1}$, Ayșe OĞUZ ÜNVER ${ }^{2}$

\section{Abstract}

STEM education is concerned with the teaching of various disciplines in an integrative way. The basic idea in this perspective, although the STEM concepts and

$\underline{\text { Keyword }}$

STEM education,

Engineering,

Engineering integration, Engineering design process. skills holistically exist in the real-world, they are tried to be acquired separately in school lessons. Engineering has particular importance for the acquisition of 21 stcentury competencies to students and supporting the transferability of these competencies which are priority aims of STEM education. Engineering incorporates specific features such as having a problem solving-focused structure, enabling the implementation of effective teaching methods with engineering design, and creating a learning environment for students to learn with their own experience. However, the main problem faced at this point is how to achieve an effective engineering integration in STEM education. In this context, with the STEM education perspective, the aim of the research is to reveal the nature of engineering based on the literature review and to examine how to achieve an effective engineering integration in STEM education theoretically. The research results revealed that the most accepted approach in the integration of engineering into STEM education is the transfer of engineering design to learning environments. Besides, the research results showed that emphasizing the basic concepts, skills, and practices related to engineering in teaching processes might increase the quality of integration and this type of integration can support the learning outcomes in the context of Turkey.

\begin{tabular}{ll}
\hline Atıf için: & Okulu, H. Z. \& Oğuz Ünver, A. (2021). Mühendisliğin STEM eğitimine entegrasyonunda \\
For Citation & kuramsal bir inceleme. Muğla Sitkı Koçman Üniversitesi Eğitim Fakültesi Dergisi [MSKU \\
& Journal of Education], 8(2), 545-558. DOI: 10.21666/muefd.841152 \\
\hline
\end{tabular}

\footnotetext{
${ }^{1}$ Muğla Sıtkı Koçman Üniversitesi, Eğitim Fakültesi, hasanokulu@mu.edu.tr, ORCID: 0000-0002-2832-9620

${ }^{2}$ Muğla Sıtkı Koçman Üniversitesi, Eğitim Fakültesi, ayseoguz@mu.edu.tr, ORCID: 0000-0003-2938-5269
} 
STEM (fen, teknoloji, mühendislik ve matematik) eğitiminin temelini oluşturan düşünce, STEM disiplinlerinin okullarda birbirinden bağımsız olarak öğretilmelerine karşın bu disiplinlerin gerçek yaşamda bütünleşik olarak yer almalarıdır (STEM Task Force Report, 2014). Öğretim süreçlerinde disiplinlere özgü kavram ve becerileri ayrık olarak edinen birey, bütünsel bakış açısına sahip olmadığı için gerçek ve mesleki yaşamda karşılaştığ problemlere tek bir disiplin kullanarak çözüm üretememektedir. Bir başka deyişle edindiği bilgi ve becerileri karşılaştığ 1 yeni durumlara transfer etmekte zorlanmaktadır (Honey, Pearson ve Schweingruber, 2014; Moore ve Smith, 2014; Wang, Moore, Roehrig ve Park, 2011). Bu sorundan hareketle STEM eğitiminin uzun vadeli hedefleri, bilime bütünsel bakış açısına sahip olan, günlük ve mesleki yaşamda karşılaştığı problemlere çözüm üretebilen bireyler yetiştirerek, sosyal ve ekonomik kalkınmanın sağlanması için nitelikli iş gücünün oluşturulmasıdır. (Bybee, 2013; National Research Council [NRC], 2011). Ancak bu noktada tüm dünyadaki eğitim sistemlerinin yüzleştiği zorluk, mevcut formal eğitimde bulunan öğrencilerin teknolojinin gelişimi ile yeni ortaya çıkan STEM alanlarında iş gücüne katılmak zorunda olmalarıdır. Aslında nitelikli STEM iş gücü ile vurgulanmak istenen 21. yüzyıl yeterlikleri olan bilişsel (bilişsel süreçler ve stratejiler, bilgi ve yaratıcılık), içsel (entelektüel açıklık, iş etiği ve titizlik, pozitif öz değerlendirme) ve kişilerarası (takım çalışması ve iş birliği ve liderlik) yeterliklere sahip bireylerdir. Bu yeterlikler, bireylerin yalnızca klişeleşmiş davranış örüntülere sahip olmak yerine değişen durumlara etkili bir şekilde uyum sağlamasına olanak tanıyan yeterliklerdir (National Research Council [NRC], 2012a). Bahsedilen yeterliklerin kalıcılığı ve transfer edilebilirliği öğretim süreçlerinde üzerinde durulması gereken en önemli değişkenlerdir. Mayer (2010) öğrenme çıktılarının kalıcıllı̆ıını ve transfer edilebilirliğini ezbere dayalı öğrenme ve anlamlı öğrenme bağlamında Tablo 1'deki şekilde sinıflandırmıştır.

Tablo 1

Ezbere Dayalı Öğrenme ve Anlamlı Öğrenme Bağlamında Öğrenme Çıktılarının Kalıcılı̆̆ı ve Transfer Edilebilirliği

\begin{tabular}{ccc}
\hline Öğrenme çıktısı türü & Kalıcılık düzeyi & Transfer edilebilirlik düzeyi \\
\hline Ezbere dayalı öğrenme & İyi & Zayıf \\
\hline Anlamlı öğrenme & İyi & İyi \\
\hline
\end{tabular}

Tablo 1'den anlaşıldığg üzere anlamlı öğrenme, çıktılarının hem kalıcılığı hem de transfer edilebilirliği bağlamında öğrenme süreçleri ile hedeflenen öğrenme çıktısı türüdür. NRC (2012a) tarafından anlamlı öğrenme, bireyin bir durumdan öğrendiklerini yeni durumlara uygulayabilme süreci olarak tanımlanmış ve anlamlı öğrenmeyi destekleyen dört temel nitelik ortaya konulmuştur:

- Konu alan bilgisi bağlamında etkili öğretim yöntemleri kullanıldığında bilginin transfer edilmesi mümkündür.

- Anlamlı öğrenme, bir alandaki iyi organize edilmiş bilginin geliştirilmesini içerir. Bu durumda bilgi, aynı alandaki yeni problemlere uygulanmak (transfer etmek) için kolayca elde edilebilir.

- Anlamlı öğrenme, öğrencilerin hataları düzeltmelerine ve doğru prosedürleri uygulamalarına yardımcı olan açıklayıcı geribildirimler yardımıyla kapsamlı bir uygulama gerektirir.

Anlamlı öğrenme ezbere dayalı öğrenmenin aksine karşılaşılan problemin yapısının ve çözüm yönteminin anlaşılmasını sağlar. Böylelikle bilginin transfer edilebilmesi sağlanır.

Yukarıda bahsedilen dört temel niteliğin öğrenme sürecinde desteklenebilmesi, nitelikli bir şekilde gerçekleştirilen mühendislik entegrasyonu ile yakından ilişkilidir. STEM eğitiminde mühendislik entegrasyonu, öğrencilerin diğer STEM disiplinleri ile ilgili bilimsel bilgi ve becerileri bütünleştirmelerini sağlayarak, problem çözme becerilerini geliştirir (Capraro ve Slough, 2008; Morrison, 2006). Bu durum ise öğrenilenlerin, yeni durumlara uygulanabilmesine, bir başka deyişle anlamlı öğrenmenin gerçekleşmesine olanak tanır. Ayrıca bu süreçte öğrenciler STEM alanlarındaki olgu, ilke ve tekniklerini deneyimleyerek öğrenirler ve elde ettikleri beceriler, hem okul hayatında hem de gerçek yaşamda birçok disipline transfer edilebilen becerilerdir (Thomasian, 2011). Mühendislik entegrasyonu içeren STEM eğitimi, öğrencilerin kendi deneyimlerini geliştirmelerine ve gerçekleştirdikleri tasarımları analiz etme ve bilimsel araştırma yoluyla yeni fen ve matematik kavramlarını yapılandırmalarına olanak tanır (Kelley ve Knowles, 2016). Sunulan bu özellikleri nedeniyle STEM eğitiminde nitelikli gerçekleştirilen bir mühendislik entegrasyonu, 21. yüzyıl yeterliklerinin kazanılmasına ve yeni durumlara transfer edilmesine katkı sağlayacak yapıdadır. $\mathrm{Bu}$ 
noktada karşılaşılan soru ise STEM eğitiminde nitelikli bir mühendislik entegrasyonunun nasıl sağlanacağıdır. $\mathrm{Bu}$ nedenle mühendislik ve mühendislik entegrasyonu içeren yaklaşımların STEM eğitimi uygulayıcıları ve alan eğitimi araştırmacıları tarafından bilinmesi, mühendislik ile STEM disiplinlerin bütünleştirilmesinin anlaşılması açısından oldukça önemlidir. Buradan hareketle, araştırmanın amacı STEM eğitimi bakış açısı ile alanyazın incelemesi temelinde mühendisliğin doğasını ortaya koymak ve STEM eğitiminde etkili bir mühendislik entegrasyonunun nasıl gerçekleştirileceğini kuramsal olarak incelemektir.

\section{Mühendislik ve Mühendisliğin Doğası}

Engineer (mühendis) kelimesi Orta çağ Latincesinde tasarlamak anlamına gelen ingeniare fiilinden kökenlenmektedir. Ingeniare fiili ise zekice buluş anlamına gelen ingenium kelimesinden türetilmiştir (Flexner, 1987). Kelime kökeninden de anlaşılacağı üzere mühendislik sıklıkla tasarım ve yaratıcılık gibi kavramlarla ilişkilendirilir. İnsanlık tarihinin her aşamasında araçlar ve yapılar yaşamın sürdürülebilmesi için vazgeçilmez ihtiyaçlar olmuşlardır. Bu nedenle tasarımlar, insanın hayatta kalma isteğinin doğal bir sonucudur. Mühendislik diyebileceğimiz en eski faaliyetlerden bazıları, M. Ö. 4. yüzyıldan M. S. 3. yüzyıla kadar Roma ve çevresindeki su kemerleri sisteminin inşası gibi projelerdir (Evans, 1994). Mühendislik, dört bin yıllık bir deneyim ve maddelerin yapısal sınırlarının anlaşılmasını sağlayan yaklaşık iki yüz yıllık bilimsel analiz süreçlerine dayanır. Mühendislik disiplininin öncülerine ait tasarımlarda nicel ölçmeye dayalı veriler ve bilimsel bilgiler çok sınırlı düzeydedir (Hill, 1996). Gille (1956)'ya göre basit makineler bu durumun istisnası olarak kabul edilir. Archimedes of Syracuse (M.Ö. 287 - M.Ö. 212) mekanik biliminin antik dönemdeki öncüsü olarak statik üzerine yaptı̆̆ araştırmalar ile kaldıraç ve ağırlık merkezi ile ilgili temel ilkeleri ortaya koymuştur. Matematik ve geometrinin kullanıldığı bu araştırmalar bilimsel süreçlerin kullanımına dayanır (Akt: Moon, 2010). Mühendislik bir uzmanlık alanı olarak Rönesans döneminde değer kazanmış ve modern anlamda askeri mimarlar ilk mühendisler olarak kabul görmüşlerdir (National Research Council [NRC], 2009). Formal anlamda ilk kez 18. yüzyılın ortalarında matematik, teknik çizim ve mühendislik teorisi gibi dersler içeren eğitim programlarının oluşturulmasıyla Fransa'da bugün bilinen çağdaş mühendislik disiplini ortaya çıkmıştır (Langins, 2004). Çağdaş anlamda mühendislik bir disiplin olmasının doğası gereği bazı temel niteliklere sahiptir. Bu nitelikler, National Academies of Sciences, Engineering, and Medicine [NASEM] (2020) ve NRC (2009) tarafından şu şekilde ifade edilmiştir:

- Mühendislik sistematik bir yapıdadır.

- Mühendislik amaç odaklıdır.

- Mühendislik döngüseldir.

- Başarısızlık mühendisliğin doğal bir parçasıdır.

- Mühendislik takım çalışmasına dayanır.

- Mühendislik doğası gereği yaratıcılık içerir ve iyimser bir bakış açısıyla her probleme çözülebilir bir sorun olarak yaklaşır.

- Mühendislik insan ürünüdür.

- Mühendislik sosyal ve etik kaygıları göz önünde bulundurur.

Yukarıda sunulan nitelikler yalnızca mühendisliğe özgü özellikler olmayıp birçok farklı disiplinle de paylaş1ır. Mühendisliğin bu niteliklerini temel alan tanımlarından bazıları Tablo 2'de sunulmuştur.

Tablo 2'den anlaşılacağı üzere mühendislik sınırlamalar dâhilinde ürün oluşturma süreçlerini içermektedir. Birçok bilim dalı için bütünleştirici bir disiplin olan mühendislikte doğa yasaları başta olmak üzere çok farklı türde sınırlama yer almaktadır. Mühendisliğin temel hedefi ise problem çözme süreçlerini kullanarak yaşamı kolaylaştıran ürünler ortaya çıkarmaktır. Bilimin diğer disiplinleri ve mühendislik yaratıcı süreçleri içermeleri ve nihai bir yönteme sahip olmamaları açılarından benzerdir (National Research Council [NRC], 2012b). Ancak yaygın bir şekilde mühendisliğe özgü yöntem mühendislik tasarımı olarak kabul görür (Haik ve Shahin, 2011). Mühendislik tasarımı Dym, Little, Orwin ve Spjut (2009) tarafından şu şekilde tanımlanmıştır:

Mühendislik tasarımı, mühendislerin belirli birtakım sınırlamalar altında biçim(leri) ve işlev(leri) müşterilerin amaçlarına ulaşan ve kullanıcıların gereksinimlerini karşılayan cihazlar, sistemler veya süreçler için çözümler üretme, değerlendirme ve tanımlamada kullandıkları sistematik ve düşünme gerektiren bir süreçtir. Başka bir ifadeyle mühendislik tasarımı, belirli sınırlamalara bağlı kalırken verilen hedeflere ulaşan cihazlar, sistemler veya süreçler için planlar veya şemalar 
oluşturmak amacıyla kullanılan derinlemesine düşünme gerektiren bir süreçtir (Dym ve diğerleri, 2009, s. 7).

Tablo 2

Mühendislik Kavramına Yönelik Bazı Tanımlar

\begin{tabular}{|c|c|}
\hline Tanım & Referans \\
\hline $\begin{array}{l}\text { Mühendislik, hem problemleri çözmek için bir süreç hem de bir bilgi bütünü olarak } \\
\text { insan yapımı ürünlerin oluşturulması ve tasarlanmasıdır. Bu süreç aslında sınırlamalar } \\
\text { bağlamında tasarım yapmakla ilgilidir. Mühendislik tasarımındaki sınırlamalardan } \\
\text { birisi doğa veya fen yasalarıdır. Mühendislik tasarımındaki diğer bazı sınırlamalar ise } \\
\text { zaman, bütçe, kullanılabilir malzemeler, ergonomi, çevre ile ilgili kanunlar, } \\
\text { üretilebilirlik ve tamir edilebilirlik şeklindedir. Mühendislik, fen ve matematik } \\
\text { kavramlarının yanı sıra teknolojik araçlardan da yararlanır. }\end{array}$ & NRC, 2009 \\
\hline $\begin{array}{l}\text { Mühendislik, maddeleri ve doğadaki enerji kaynaklarını yapılarda, makinelerde ve } \\
\text { ürünlerde insanlar için yararlı hale getiren bilimdir. }\end{array}$ & Licker, 2003 \\
\hline $\begin{array}{l}\text { Mühendislik, sınırlamalara göre gerçekleştirilen tasarımlarla ilgilidir. Mühendisler } \\
\text { cihazları, bileşenleri, sistemleri ve alt sistemleri tasarlarlar. Doğrudan veya dolaylı } \\
\text { olarak yaşam kalitemizin iyileşmesini sağlayan bu tasarımlar teknik, ekonomik, } \\
\text { politik, sosyal ve etik konuların getirdiği sınırlamalar dahilinde geliştirilir. }\end{array}$ & $\begin{array}{l}\text { National Academy of } \\
\text { Engineering, } 2004\end{array}$ \\
\hline
\end{tabular}

International Technology Education Association [ITEA] (2000) mühendislik tasarımının sahip olduğu karakteristik özellikleri amaç odaklı olma, belirli gereksinimlere dayanma, sistematik ve döngüsel olma, doğasında yaratıcılık barındırma ve tasarım probleminin çözümüne yönelik çoklu çözüm yolları içerme olarak belirtmiştir. Tasarım sürecinin temel amacı mühendislik probleminin çözümüdür. Mühendislik problemleri ise çoğunlukla yapılandırılmamış (açı uçlu) problemlerdir. Bu nedenle tasarımın döngüsünün amaç odaklı yapısında tasarım hedeflerini netleştirmek ilk önceliktir. Bu durum, tasarımın her aşamasında tasarım ile ilgili net bir fikre sahip olmak adına çok yararlıdır (Cross, 2008). Bir tasarımın başarısı, gereksinimleri karşılamasına bağlıdır. Bu gereksinimler tasarımın amacı ile ilişkilidir ve sınırlamalar doğrultusunda şekillenir (Haik ve Shahin, 2011). Mühendislik tasarımının sistematik yapısı belirli yöntem ve teknikleri içerir. Örneğin bir tasarım için gereksinimleri açık bir şekilde ortaya koymak amacıyla kullanılan hiyerarşik hedef ağacı tekniği veya tasarım hedeflerinin önceliklerine göre yüksek, orta veya düşük olarak sıralandığı öncelik puantaj yöntemi bunlardan bir kaçıdır (Dym ve diğerleri, 2009). Mühendislik probleminin ortaya konulmasından gereksinimleri karşılayan bir tasarım oluşturulmasına kadar geçen süreç doğrusal değil, döngüseldir. Tasarım aşamalarında elde edilen yeni bir bilgi veya tasarımdan elde edilen bir veri, sürecin önceki aşamalarına geri dönülmesini gerektirebilir (Simon, 1975). Sistematik bir tasarım sürecinde yaratıcılık tüm aşamalarda kullanılır. Tasarım süreci bağlamında yaratıcılık çoğunlukla fikir üretmeyle ilişkilidir. $\mathrm{Bu}$ nedenle farklı fikirlerin ortaya konulmasına ve değerlendirilmesine dayalı beyin firtınası, grup odaklı mühendislik tasarımında kullanılan en yaygın tekniktir (Haik ve Shahin, 2011). Bir tasarım probleminin birden çok olası çözümü bulunabilir. Bir durum için en iyi olarak görünen bir çözüm, bir başka durum için en uygun çözüm olmayabilir. Mühendislik tasarımında bu tip durumlar için birçok olası çözüm üretilir ve bu çözümler arasından en iyi çözüm belirli koşullara bağlı olarak belirlenir (ITEA, 2000). Mühendislik tasarımının karakteristik özellikleri mühendislik disiplininin uzun yıllar boyunca oluşturduğu deneyime ve bilimsel kanıtlara dayalı olarak şekillenmiştir. Bu özellikler her tasarım için mutlak olmasa da bir mühendisi amatör bir mucitten veya bir tamirciden ayıran temel kurallar ve ilkelerdir (NRC, 2009). Tasarım problemlerinin çözümünde tek ve mutlak bir mühendislik tasarım süreci bulunmaz. Ancak mühendislik tasarım süreçlerinin genel hatları birbirine çok benzerdir (Boesdorfer ve Greenhalgh, 2014). Mühendislik tasarımı, problemin net bir şekilde tanımlanması ile başlar. Mühendislik probleminin nasıl çözüleceğine dair fikirler üretilmesi ile devam eder. Bilimsel araştırma süreçleri ve beyin firtınasına dayalı tartışmalar sıklıkla alternatif tasarım fikirlerini geliştirmek için kullanılır. Tasarım çözümleri bağlamında prototipler ve/veya modeller oluşturulur ve test edilir. Test etme aşaması başka yollarla elde edilemeyecek verileri sağlamak için potansiyel çözümlerin değerlendirilmesidir. Eldeki verilerle çeşitli çözümlerin tasarımın gereksinimlerine ne derece hizmet ettiği ve sınırlamaları ne derece karşıladığı değerlendirilir. Optimizasyon olarak nitelendirilen bu süreçte sınırlamalar ve gereksinimler arasında bir denge kurulur (NRC, 2009). 


\section{Mühendisliğin STEM Eğitiminde Öğretim Süreçlerine Entegrasyonu}

STEM eğitiminde entegrasyon kavramı fen, teknoloji, mühendislik ve matematik disiplinlerinin bir öğretim programı, ünite veya ders içerisinde disiplinler arası ilişkilere ve gerçek dünya problemlerine dayalı olarak bütünleştirilmesini ifade etmek için kullanılır (Moore ve Smith, 2014). Alanyazında STEM eğitiminde mühendislik entegrasyonunun nasıl gerçekleştirileceğine dair farklı yaklaşım ve modeller mevcuttur (Berland, 2013; English ve King, 2015; Roehrig, Moore, Wang ve Park, 2012). Moore ve Smith (2014) içerik ve mühendislik ile ilgili fikirlerin entegre edilmesi için bağlam ve içerik entegrasyonu olmak üzere iki farklı entegrasyon modeli önermektedir. Bağlam entegrasyonunda genellikle fen ve matematik ile ilgili kavramların öğretiminde mühendislik tasarım süreci bir motivasyon aracı olarak kullanılır. Öğrenme hedefleri doğrudan mühendislik ile ilgili değildir. $\mathrm{Bu}$ süreçte mühendislik tasarımı öğrencilerin içeriği öğrenmeleri için bir öğrenme yaklaşımı olarak ele alınır. İçerik entegrasyonu ise mühendislik fikirleri ile matematik ve fen içeriğinin doğrudan entegre edilmesi anlamına gelir. Bu modelde çoklu alanlarda öğrenmeye vurgu yapılır. Matematik ve fen içeriği ile mühendislik, öğrenme hedeflerinin bir parçası olarak değerlendirilir. STEM eğitimine mühendislik entegrasyonu için sıklıkla tasarım görevlerinden (design challenges) yararlanılır. Öğrencilere bir mühendislik problemi veya tasarım görevi sunulur. Öğrenciler verilen görevi tamamlamak için mühendislik tasarım sürecini kullanırlar. Süreçte uygulayıcının rehberliğinde fen ve matematik kavram ve becerileri ile teknolojik araçların kullanımı temel alınır (Berland, 2013; English ve King, 2015; Estapa ve Tank, 2017; Guzey, Moore ve Harwell, 2016). Bu tür entegrasyon, yeni bir konunun öğretimi için doğrudan tasarım görevlerinin öğrencilere sunulması ile gerçekleştirebileceği gibi işlenen bir konuda öğrencilerin öğrenme deneyimlerinin derinleştirilmesi için de kullanılabilir. Bu durumda ögrenciler önceki derslerde edindikleri kavram ve becerileri kullanarak bir tasarım görevini gerçekleştirirler (Roehrig ve diğerleri, 2012). Alanyazından anlaşılacağı üzere mühendisliğe dayalı STEM entegrasyonunda en çok kabul gören yaklaşım mühendislik tasarımının öğretim süreci ile bütünleştirilmesidir. Ancak mühendislik tasarımı mühendislerin mesleki yaşamlarında kullandığı bir yöntemdir. $\mathrm{Bu}$ nedenle mühendislik tasarımı öğretim süreçlerinin dinamikleri (zaman, öğrencilerin zihinsel ve fiziksel gelişim düzeyleri ve öğretim programının yapısı gibi) göz önünde bulundurularak farklı şekillerde öğretim süreçlerine uyarlanır. Mühendisliğin STEM öğretim süreçlerine entegrasyonu için yaygın bir şekilde kullanılan bazı mühendislik tasarım süreçleri Şekil 1'de sunulmuştur.

Şekil 1'de yer alan NASA mühendislik tasarım süreci NASA mühendislerinin kullandığı problem çözme süreçlerine vurgu yapmaktadır. Tasarım sürecinin ilk adımı olan soru sorma aşamasında problem tanımlanır. Tasarım gereksinimleri, sınırlamalar da göz önünde bulundurularak belirlenir. Çözüme yönelik beyin firtınası tekniğinin kullanıldığı, belirlenen fikirlere yönelik araştırma yapıldığı aşama, hayal etme aşamasıdır. Bu aşamada benzer bir problemin çözümüne yönelik gerçekleştirilen çalışmalar da incelenir. Planlama aşamasında, beyin firtınası tekniği ile elde edilen tasarım çözümlerinden iki veya üç tanesi seçilir. Bu tasarım çözümlerine ilişkin çizimler oluşturulur. Çizimlerden birisi prototip tasarımı için belirlenir. Tasarım gereksinimlerine uygun ve tasarım sınırlamalarını içeren işlevsel bir model veya prototipin üretildiği aşama ise oluşturma aşamasıdır. Test etme aşamasında tasarım çözümü test edilerek değerlendirilir. Bu noktada veri toplama ve analiz etme süreçleri kullanılır. Tasarımın test edilmesiyle ortaya çıkan güçlü ve zayıf yönler ortaya konulur. Test etme sürecinden elde edilen verilere dayalı olarak tasarımda iyileştirmelerin yapıldığı aşama ise geliştirme aşamasıdır. Ayrıca bu aşamada yapılan iyileştirme ifade edilir. Bu iyileştirmenin test aşamasındaki hangi veriden kaynaklandığına dair kanıtlar ortaya konulur (NASA, 2011).

Şekil 1'de görülen EiE mühendislik tasarım süreci ise tasarım görevleri bağlamında ilkokul ve ortaokul fen konuları ile mühendislik tasarım sürecinin entegre edilmesine dayalıdır. Soru sorma aşaması, mühendislik probleminin belirlendiği, benzer problemin çözümüne yönelik gerçekleştirilen çalışmaların incelendiği ve sınırlamaların ortaya konulduğu aşamadır. Hayal etme aşamasında ise problemin çözümüne yönelik fikirler ortaya konulur, beyin firtınası gerçekleştirilir ve çözüme yönelik en iyi fikir seçilir. Çözüm kapsamında taslak bir çizimin oluşturulduğu ve gerekli malzemelerin listelendiği aşama ise planlama aşamasıdır. Oluşturma aşamasında taslak çizime göre prototip oluşturulur ve test edilir. Geliştirme aşaması, test sürecinden elde edilen verilerden hareketle tasarımın işleyen ve işlemeyen yönlerinin belirlenmesi ve tasarımın nasıl geliştirilebileceğine yönelik tartışma ile başlar. Bu tartışmaya göre tasarım revize edilir ve yeniden test süreci işletilir (Cunningham ve Hester, 2007). 


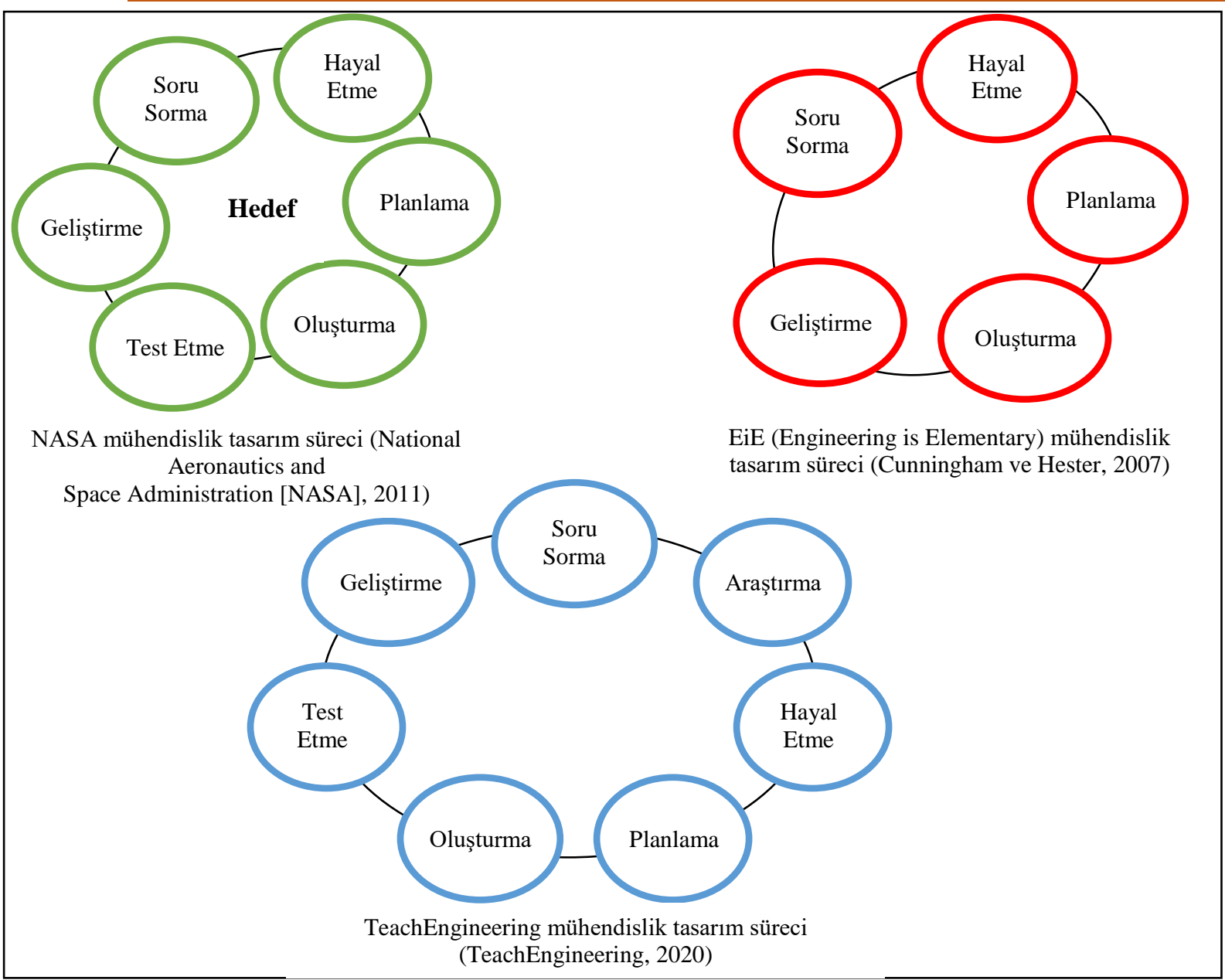

Şekil 1 STEM Öğretim Süreçlerine Mühendislik Entegrasyonu için Yaygın Bir Şekilde Kullanılan Mühendislik Tasarım Süreçleri

Şekil 1'de yer alan TeachEngineering mühendislik tasarım süreci ise proje tabanlı öğrenme ve grup çalışması temelinde fen ve matematik kavramlarının öğretim süreçlerine aktarılmasına dayanmaktadır. $\mathrm{Bu}$ tasarım sürecinin soru sorma aşaması, tasarım problemi bağlamında gereksinimlerin ve sınırlamaların belirlenmesi ile başlar. Bu aşamada problemin tanımlanması için, çözülmesi gereken sorun nedir, tasarlanmak istenen nedir, tasarımın hedef kitlesi nedir, tasarımla başarılmak istenen nedir, tasarım gereksinimleri nelerdir, tasarım sınırlamaları nelerdir ve tasarım hedefi nedir? gibi sorulara yanıt aranır. Araştırma aşaması ise hangi ürünlerin veya çözümlerin tasarım probleminin yanıtlanması için mevcut olduğunu veya hangi teknolojilerin gereksinimler çerçevesinde problemin çözümünde kullanabileceğini belirlemeyi amaçlar. Bu süreç farklı deneyime ve uzmanlığa sahip insanlarla iletişim kurmayı içerir. Hayal etme aşaması ise problemin çözümü için olası çözümlerin geliştirilmesine dayanır. Beyin firtınası tekniği ile gerçekleştirilen grup tartışmaları, problemin çözümüne ilişkin mümkün olduğu kadar farklı fikrin ortaya çıkmasını sağlar. Planlama aşamasında gereksinimler ve sınırlamalar göz önünde bulundurularak ve araştırma aşamasında elde edilen veriler değerlendirilerek problemin yanıtlanması için en iyi çözüm seçilir. İlerleyen aşamalar için çizimleri içeren planlama yapılır. Prototipin tasarlandığı aşama ise oluşturma aşamasıdır. Test etme aşamasında tasarımın çalışıp çalışmadığı ve gereksinimleri karşılayıp karşılamadığı değerlendirilir. Elde edilen sonuçlar paylaşılır ve sonuçlara yönelik dönüt sağlanır. Tasarımın işleyen ve işlemeyen yönleri ile daha fazla nasıl geliştirilebileceğine yönelik analizler geçekleştirilir ve paylaşılır. Eğer gerekli ise süreçte geliştirme aşaması işletilir. Bu aşamada tasarım çözümünün geliştirilmesi için tartış1lır. Revizyonlar yapılır ve yeni/revize edilmiş çizimler hazırlanır. Tasarım mümkün olan en nitelikli hale getirilmeye çalışılır (TeachEngineering, 2020).

Sunulan mühendislik tasarım süreçleri (Cunningham ve Hester, 2007; NASA, 2011; TeachEngineering, 2020) değerlendirildiğinde birbirine benzer bir yapıya ve akışa sahip oldukları anlaşılabilir. Genel olarak 
grup çalışmasına dayalı mühendislik tasarım süreçleri belirli problemin çözümüne odaklanır. Öncelikle problemin çözümüne ilişkin bilgi toplanır ve araştırma yapılır. Elde edilen kanıtlar temelinde farklı çözüm yolları tartışılır. Bu çözüm yollarından gereksinimleri ve sınırlamaları en iyi karşılayan çözüm yolu seçilir. Çözüm yoluna yönelik çizimler oluşturulur. Tasarımda kullanılacak malzeme ve yöntemlere karar verilir. Sonrasında prototipler oluşturulur ve test edilir. Ürün tasarımı, gereksinimleri karşılayacak kadar nitelikli olana kadar iyileştirmeler (revizyonlar) gerçekleştirilir. Genel hatları sunulan mühendislik tasarımının STEM eğitiminde kullanılması nitelikli bir mühendislik entegrasyonunun gerçekleştirilebileceği anlamına gelmemektedir. Bu bağlamda önemli bir diğer değişken, mühendislik ile ilgili kavram ve becerilerin de öğretim sürecine yansıtılmasıdır. NRC (2009) bu kavram ve becerileri öğrenme süreçlerinde yer alması beklenen temel mühendislik kavram ve becerileri olarak tanımlamış ve şu şekilde sınıflandırmıştır:

- Temel fen ve matematik kavramları: Mühendisliğin tasarım oluşturma süreçlerinde temel fen ve matematik kavramlarından yararlanması bir zorunluluktur. Örneğin, sürtünme kuvveti ve integral gibi.

- Alana özgü kavramlar: Mühendisliğin alt disiplinleri kendine özgü kavramlar içerir. Entegrasyonda yararlanılan alt mühendislik disiplinine özgü kavramlar sürece dahil edilmelidir. Örneğin, havacılık ve uzay mühendisliği için kanat yakıt hacmi ve tırmanma hızı gibi.

- Mühendisliğin çoğu alanında ortak olarak yer alan kavramlar: Mühendislik alt disiplinleri birçok ortak kavramı paylaşır. Belirtilen kavramlar disiplin içerisinde ortak bir dil oluşturur. $\mathrm{Bu}$ kavramların entegrasyon sürecine dahil edilmesi mühendisliğin doğasının anlaşılmasına katkı sağlar. Örneğin, tasarım gereksinimleri, prototip, optimizasyon ve alt sistemler gibi.

- Mühendislik becerileri: Bu beceriler ağırlıklı olarak mühendislik tasarım sürecinde kullanılan becerilerdir ve tasarım sürecinde öğrencilerin kendi deneyimleri ile bu becerileri geliştirmeleri desteklenmelidir. Örneğin, problemi tanımlanma becerisi gereksinimleri belirme becerisi, çözüm üretme becerisi, çizim ve gösterimleri oluşturma becerisi gibi.

Ayrıca entegrasyon sürecine, bu kavram ve becerilere ek olarak öğrencilere mühendisliğe yönelik zihin alışkanlığı kazandırmayı hedefleyen mühendislik uygulamalarının da dahil edilmesi beklenir (NRC, 2012b). Bu düşüncenin temelini Amerika Birleşik Devletleri'nde Gelecek Nesil K-12 Fen Standartları içerisinde STEM eğitiminin ağırlıklı olarak mühendislik entegrasyonuna dayanması (Gencer, Doğan, Bilen ve Can, 2019) oluşturur. Fen ve mühendislik uygulamaları, kesişen kavramlar ve disipline özgü temel fikirler olmak üzere üç boyuttan oluşan bu standartlar arasında mühendislik vurgusu, fen ve mühendislik uygulamalarında yer almaktadır (National Research Council [NRC], 2013). Tablo 4'te bahsedilen uygulamalar bağlamında mühendislik disiplinine özgü nitelikler sunulmuştur.

Tablo 4'te yer alan uygulamalara mühendislik entegrasyonu içeren STEM eğitimi süreçlerinde yer verilmesi, öğrencilerin mühendisliğin doğasını anlamaları, mühendislerin nasıl çalıştıklarını içselleştirmeleri ve mühendislik ile diğer disiplinler arasındaki bağlantıları kavramaları adına oldukça önemlidir (NRC, 2012b). Mühendislik entegrasyonu içeren STEM eğitiminin başarısı doğrudan öğrenme çıktıları ile ilişkilendirilebilir. Türkiye bağlamında mühendisliğin STEM eğitimine entegrasyonunu konu alan araştırmaların incelenmesi, bu tür uygulamaların öğrenme çıktıları üzerine etkisini değerlendirebilmek adına oldukça faydalı olacaktır. 
Tablo 4

Fen ve Mühendislik Uygulamaları Băglamında Mühendislik Disiplinine Özgü Nitelikler (NRC, 2012b'den uyarlanmıştır)

\begin{tabular}{|c|c|}
\hline Uygulama & Mühendislik niteliği \\
\hline $\begin{array}{l}\text { Sorular sorma ve } \\
\text { problemleri } \\
\text { tanımlama }\end{array}$ & $\begin{array}{l}\text { Mühendislik bir sorun, ihtiyaç veya istekten kaynaklanan ve çözülmesi gereken bir } \\
\text { problem ile başlar. Mühendisler, mühendislik problemini tanımlamak, başarılı bir çözüm } \\
\text { için ölçütleri belirlemek ve tasarım sınırlamalarını ortaya koymak için sorular } \\
\text { oluştururlar. }\end{array}$ \\
\hline $\begin{array}{l}\text { Modelleri } \\
\text { geliştirme ve } \\
\text { kullanma }\end{array}$ & $\begin{array}{l}\text { Mühendislik var olan sitemlerdeki kusurları belirlemek için analiz işlemleri gerçekleştirir. } \\
\text { Bu analizlerde ise modellerden ve simülasyonlardan faydalanılır. Modeller ve } \\
\text { simülasyonlar yeni bir mühendislik probleminin olası çözümlerini test etmek için de } \\
\text { kullanılır. Ayrıca, mühendisler önerilen sistemleri test etmek ve tasarımlarının güçlü } \\
\text { yönlerini ve sınırlamalarını ortaya koymak için farklı türdeki modellere başvururlar. }\end{array}$ \\
\hline $\begin{array}{l}\text { Araştırmayı } \\
\text { planlama ve } \\
\text { gerçekleştirme }\end{array}$ & $\begin{array}{c}\text { Mühendisler tasarım ölçütlerini ve dayanaklarını detayları ile belirlemek için veri elde } \\
\text { etmek durumundadırlar. Bu amaçla bilimsel araştırma süreçlerini kullanırlar. Ayrıca } \\
\text { tasarımların test edilmesi için de bilimsel araştırma süreçleri vazgeçilmezdir. } \\
\text { Mühendislerin çalışılan konu ile ilgili değişkenleri tanımlamaları, bu değişkenlerin nasıl } \\
\text { ölçüleceğine karar vermeleri ve analiz için veri toplamaları gereklidir. Bu araştırma } \\
\text { süreçleri, tasarımlarının belirli koşullar altında ne kadar etkili, verimli ve dayanıklı } \\
\text { olabileceğini belirlemeye yardımcı olur. }\end{array}$ \\
\hline $\begin{array}{c}\text { Verilerin analizi } \\
\text { ve yorumlanması }\end{array}$ & $\begin{array}{l}\text { Mühendisler, tasarımların test aşamasında toplanan ve bilimsel araştırma süreçlerinde } \\
\text { elde edilen verileri analiz eder. Bu durum farklı tasarım çözümlerinin karşılaştırılmasına } \\
\text { ve her bir çözümün belirli tasarım ölçütlerini ne düzeyde karşıladığının belirlenmesine } \\
\text { olanak tanır. Böylelikle mühendisler hangi tasarımın belirlenen sınırlamalar bağlamında } \\
\text { mühendislik problemini en iyi şekilde çözdüğünü belirleyebilirler. Verilerin analizi ve } \\
\text { yorumlanması sürecinde mühendisler önemli örüntüleri tanımlamak ve sonuçları } \\
\text { yorumlamak için birçok araca ihtiyaç duyarlar. }\end{array}$ \\
\hline $\begin{array}{l}\text { Matematiği ve } \\
\text { hesaplamalı } \\
\text { düşünmeyi } \\
\text { kullanma }\end{array}$ & $\begin{array}{l}\text { Mühendislikte, kurulan ilişkilerin ve ilkelerin matematiksel ve sayısal gösterimleri } \\
\text { tasarımın ayrılmaz bir parçasıdır. Buna ek olarak, tasarım simülasyonları, tasarımların } \\
\text { geliştirilmesi ve iyileştirilmesi için etkili bir sınama ortamı sunar. }\end{array}$ \\
\hline $\begin{array}{l}\text { Açılamalar } \\
\text { oluşturma ve } \\
\text { çözümleri } \\
\text { tasarlama }\end{array}$ & $\begin{array}{l}\text { Mühendislik problemlerini çözmek için sistematik bir süreç olan mühendislik tasarımı, } \\
\text { bilimsel bilgi ve maddesel dünyaya ilişkin modellere dayanır. Önerilen her çözüm, } \\
\text { istenilen işlevlere, teknolojik alt yapıya, maliyete, güvenliğe, estetik ve yasal } \\
\text { gereksinimlere uyuma ilişkin ölçütlerin dengelenmesinden ortaya çıkmaktadır. Bu süreçte } \\
\text { genel olarak mutlak bir çözüm yerine birçok çözüme vurgu yapılır. Bu çözümlerin } \\
\text { hangisinin en iyi seçim olduğu, değerlendirme yapmak için kullanılan ölçütlerle ilintilidir. }\end{array}$ \\
\hline $\begin{array}{l}\text { Kanıta dayalı } \\
\text { argümanlarla } \\
\text { meşgul olma }\end{array}$ & $\begin{array}{c}\text { Mühendislikte, bir problemin mümkün olan en iyi çözümü bulmak için bilimsel akıl } \\
\text { yürütme ve argümanlar esastır. Mühendisler, tasarım süreci boyunca akranlarıyla iş birliği } \\
\text { yaparlar. Bu süreçteki en kritik aşama farklı ya da zıt fikirler arasından en uygun } \\
\text { çözümün seçimi olur. Mühendisler, problemin en iyi çözümüne ulaşabilmek için } \\
\text { alternatifleri karşılaştırmak, tasarımın testlerine dayanan kanıtları formüle etmek, } \\
\text { sonuçlarını savunmak için kanıtlara dayalı argüman üretmek, akranlarının fikirlerini } \\
\text { eleştirel bir şekilde değerlendirmek ve tasarımlarını revize etmek için sistematik } \\
\text { yöntemler kullanmak durumundadırlar. }\end{array}$ \\
\hline $\begin{array}{l}\text { Bilgiyi sağlama, } \\
\text { değerlendirme ve } \\
\text { bilgi iletişimi }\end{array}$ & $\begin{array}{l}\text { Mühendislerin yeni veya geliştirilmiş teknolojik ürünleri üretilebilmesi, tasarımlarının } \\
\text { yararlarını net ve ikna edici bir şekilde paylaşmalarına bağlıdır. Mühendisler, akranlarıyla } \\
\text { görüşmeler gerçekleştirerek fikirlerini sözlü ve yazılı olarak ifade ederler. Bu süreçte } \\
\text { tablolar, grafikler, çizimler veya modeller kullanabilirler. Mühendisler meslektaşlarının } \\
\text { metinlerinden anlam çıkarabilir, bilgileri değerlendirebilir ve faydalı bir şekilde } \\
\text { uygulayabilirler. Bu bağlamda mühendislikte iş birliği ve iletişim olanaklarını geliştiren } \\
\text { yeni teknolojilerin kullanımı oldukça yaygındır. }\end{array}$ \\
\hline
\end{tabular}




\section{Türkiye bağlamında mühendisliğin STEM eğitimine entegrasyonu}

Amerika Birleşik Devletleri'nde ortaya çıkan STEM eğitiminin Türkiye'de yaygınlaşmasında STEM alanında eğitim almış işgücüne yönelik talep ve beklentiler araştırması (Türk Sanayicileri ve İș İnsanları Derneği [TÜSİAD], 2014), STEM eğitimi Türkiye raporu (Aydeniz ve diğerleri, 2015) ve STEM eğitim raporu (Milli Eğitim Bakanlığı [MEB], 2016) olmak üzere üç raporun oldukça önemli bir yere sahip olduğu söylenebilir. Örneğin, TÜSİAD (2014), STEM alanlarındaki iş gücü talebinin gelecekte özellikle mühendislik disiplinlerinde artacağını ve eğitim sisteminin her kademesinde öğrencilerin STEM becerilerinin desteklenmesi gerektiğini belirtmiş̧ir. Ayrıca, Aydeniz ve diğerleri (2015) ve MEB (2016) mühendislik disiplininin STEM eğitiminin oldukça önemli bir bileşeni olduğunu, ancak Türk eğitim sisteminde bu disipline yeterli düzeyde yer verilmediğini ortaya koymuştur. $\mathrm{Bu}$ iki raporda da mühendisliğin STEM eğitimi aracılı̆̆ıyla öğretim programlarına entegrasyonunun sağlanması vurgulanmıştır. Bu kapsamda 2018 yılında güncellenen fen bilimleri dersi öğretim programında öğrencilerin mühendislik ve tasarım becerilerinin gelişiminin desteklenmesi gerektiği belirtilmiş ve günlük yaşam problemleri çerçevesinde fen, mühendislik ve girişimcilik uygulamalarının interdisipliner bir yapıda öğrencilere sunulması hedeflenmiştir (Milli Eğitim Bakanlığg [MEB], 2018). Bu duruma paralel olarak Türkiye bağlamında yapılan pek çok STEM eğitimi araştırmasının mühendislik tasarım sürecine dayalı olarak gerçekleştirildiği görülmektedir (Akgündüz ve Akpınar, 2018; Ayar, 2015; Aydın Günbatar, Tarkın Çelikkıran, Kutucu ve Ekiz Kıran, 2018; Baran, Canbazoğlu Bilici, Mesutoğlu ve Ocak, 2016; Bozkurt Altan, Yamak ve Buluş Kırıkkaya, 2016; Bozkurt Altan, Yamak, Buluş Kırıkkaya ve Kavak, 2018; Ercan ve Şahin, 2015; Marulcu ve Sungur, 2012; Özçelik ve Akgündüz, 2017; Özkızılcık ve Cebesoy, 2020; Şahin ve Kabasakal, 2018; Uysal ve Cebesoy, 2020; Yamak, Bulut ve Dündar, 2014; Yıldırım ve Altun, 2015). İncelenen ulusal düzeydeki STEM eğitimi çalışmalarında doğrudan mühendislik ile ilgili kavram ve becerilerin gelişimine odaklanan içerik entegrasyonuna dayalı araştırmalar (Ayar, 2015; Baran ve diğerleri, 2016; Marulcu ve Sungur, 2012) yer aldığ1 gibi, mühendisliği/mühendislik tasarım sürecini fen ve matematik disiplinlerinde yer alan kavram ve becerilerin öğretimi için bağlam olarak kullanmayı amaçlayan araştırmalar da (Ercan ve Şahin, 2015; Özkızılcık ve Cebesoy, 2020; Şahin ve Kabasakal, 2018; Uysal ve Cebesoy, 2020) bulunmaktadır. Bu araştırmaların sonuçları genel olarak değerlendirildiğinde mühendislik disiplinine dayalı STEM eğitiminin akademik başarıyı artırdığı (Aydın Günbatar ve diğerleri, 2018; Ercan ve Şahin, 2015; Yıldırım ve Altun, 2015), mühendislik becerilerini geliştirdiği (Ayar, 2015; Aydın Günbatar ve diğerleri, 2018), bilimsel süreç becerilerini desteklediği (Uysal ve Cebesoy, 2020; Yamak ve diğerleri, 2014), STEM becerilerini geliştirdiği (Baran ve diğerleri, 2016), 21. yüzyıl becerilerinin gelişimine katkı sağladığı (Akgündüz ve Akpınar, 2018) görülmektedir. Bu bağlamda, ulusal alanyazında mühendisliğin STEM eğitimine entegrasyonunu konu alan araştırmalar STEM eğitiminin doğasına uygun olarak Türk eğitim sistemine ve kültürüne etkili şekilde yansitılabileceğine yönelik kanıtlar ortaya koymaktadır.

\section{Sonuç ve Öneriler}

STEM alanlarında yetişmiş nitelikli iş gücü, 21. yüzyll yeterliklerine sahip bireyler olarak değerlendirilmektedir (NRC, 2012a). Bu bağlamda formal eğitimden beklenen, öğrencilerin kavram ve becerileri edinmeleri ve bunları yeni karşılaştıkları durumlara uygulayabilmeleridir. STEM eğitiminde mühendislik entegrasyonu öğrencilerin 21. yüzyıl yeterliklerinin gelişimi ve anlamlı öğrenmenin gerçekleşmesi adına önemli bir potansiyele sahiptir. Ancak bu süreçte temel değişken gerçekleştirilen entegrasyonun niteliğidir. Uygulama boyutunda STEM eğitimine mühendislik entegrasyonunun niteliği ise mühendisliğin doğasının uygulayıcı tarafından tam olarak içselleştirilmesi ve etkili bir şekilde ögretim sürecine yansıtılması ile ilgilidir. Bu bağlamda, STEM eğitiminde nitelikli bir mühendislik entegrasyonunun nasıl gerçekleştirilebileceğine ilişkin alanyazın ışığında şu değerlendirmeler ve uygulayıcılara yönelik öneriler yapılabilir:

- STEM eğitimine mühendislik entegrasyonunda genel olarak kabul gören yaklaşım mühendislik tasarımının öğretim süreçlerinde kullanılmasıdır (Berland, 2013; English ve King, 2015; Estapa ve Tank, 2017; Guzey, Moore ve Harwell, 2016). Döngüsel bir yapıda ve grup çalışmasına dayalı olan bu süreç problemin tanımlanması, gereksinimlerin ve sınırlamaların belirlenmesi, tasarım çözümlerinin ortaya konulması, tasarım çözümlerinden birisinin seçilmesi, tasarım 
çözümüne yönelik çizimlerin oluşturulması, prototip oluşturma, test etme ve geliştirme aşamalarını içerir (Cunningham ve Hester, 2007; NASA, 2011; TeachEngineering, 2020).

- STEM eğitiminde mühendislik tasarım sürecinden yararlanılması, öğrenme hedefleri dolayısıyla öğrenme çıktıları göz önünde bulundurulduğunda istenen düzeyde bir bütünleştirmeye hizmet etmeyebilir (Roehrig ve diğerleri, 2012). Bu bağlamda öğretim sürecine temel mühendislik kavram, beceri (NRC, 2009) ve uygulamaların (NRC, 2012b) yansitılmasi nitelikli bir entegrasyonun sağlanması anlamında önemlidir.

- Yalnızca mühendislik kavram ve becerilerini içeren mühendislik tasarımına dayalı etkinlikler STEM eğitiminin doğasını yansıtmaz. Mühendislik entegrasyonu içeren STEM eğitimi fen, matematik ve teknoloji disiplinlerine özgü/ortak kavram ve becerilerinin bir araya getirilmesine dayanır (Morrison, 2006).

- Hatalar ve başarısızlıklar mühendisliğin doğal bir parçasıdır (NASEM 2020; NRC, 2009). Ancak günümüzde STEM eğitimi ya da STEM projesi olarak sıklıkla fen bilimleri dersinde karşılaşılan etkinlikler bu durumu göz ardı eder niteliktedir. Örneğin, bir mancınık tasarımı etkinliği uygulayıcının "Bugün mancınık tasarlayacağız." cümlesi ile başlar ve önceden hazırlanmış bir mancınık modelini öğrencilere sunması ile devam eder. Malzemeler veya hazır etkinlik kitleri öğrencilere dağıtılır. Etkinlikte öğrenciler modeli temel alarak veya kopyalayarak tasarımlarını gerçekleştirir. Süreçte öğrencinin hata yapmasına veya hatalardan öğrenmesine izin verilmez ve öğrencinin karşılaştığı problemler uygulayıcı tarafından çözülür. Öğrenciler veri toplama ve tasarım geliştirme aşaması işletilmeden birkaç deneme yaparlar ve etkinlik sonlandırılır. Bu etkinlik özetinde temel amaç süreç değil sonuç, bir başka deyişle ürünün bir şekilde tamamlanmasıdır. Mühendislik entegrasyonu içeren STEM eğitimi etkinliklerinde, mühendisliğin doğasının yansıtılamadığı ya da kısmen yansıtılabildiği bu tür etkinlikleri STEM eğitimi yerine sözde STEM eğitimi olarak tanımlamak daha doğru olacaktır. STEM eğitiminin uygulama boyutunda hatalar öğrencilerin kendi öğrenmelerini şekillendirmeleri adına öğrenme firsatları oluşturur. Aslında mühendislik tasarım sürecinin prototipi test etme ve geliştirme aşamaları doğrudan bu amaca hizmet eder. STEM eğitimi uygulayıcılarından mühendislik tasarım sürecinde öğrencilerin karşılaştıkları hataları düzeltmeye çalışmak yerine onlara rehberlik ederek hatalarından öğrenmelerini desteklemeleri beklenir.

Türkiye bağlamında gerçekleştirilen birçok uygulamalı araştırma mühendisliğin, mühendislik tasarım süreci ile STEM eğitimine entegrasyonunu konu almaktadır. Bu araştırmalar (Aydın Günbatar ve diğerleri, 2018; Bozkurt Altan ve diğerleri, 2018; Ercan ve Şahin, 2015) bu tür bir entegrasyonun ögrencilerin STEM bilgi ve becerilerini destekleyici nitelikte olduğuna dair kanıtlar sunmaktadır. İlgili araştırma sonuçları, mühendisliğin STEM eğitimi ile bütünleştirilerek Türk eğitim sistemi ve kültürüne aktarılmasının uygulama boyutunda oldukça yararlı olacağını ortaya koymaktadır.

\section{Kaynakça}

Akgündüz, D. ve Akpınar, B. C. (2018). Okul öncesi eğitiminde fen eğitimi temelinde gerçekleştirilen STEM uygulamalarının öğrenci, öğretmen ve veli açısından değerlendirilmesi. Yaşadıkça Eğitim, 32(1), 1-26.

Altan, E. B., Yamak, H. ve Kırıkkaya, E. B. (2016). Hizmet öncesi öğretmen eğitiminde FETEMM eğitimi uygulamalar1: Tasarım temelli fen eğitimi. Trakya Üniversitesi Eğitim Fakültesi Dergisi, 6(2), 212-232.

Altan, E. B., Yamak, H., Kirikkaya, E. B. \& Kavak, N. (2018). The use of design-based learning for STEM education and its effectiveness on decision making skills. Universal Journal of Educational Research, 6(12), 2888-2906. doi:10.13189/ujer.2018.061224

Ayar, M. C. (2015). First-hand experience with engineering design and career interest in engineering: An informal STEM education case study. Educational Sciences: Theory \& Practice, 15(6), 16551675. doi: 10.12738/estp.2015.6.0134

Aydeniz, M., Çakmakcı, G., Cavaş, B., Özdemir, S., Akgündüz, D., Çorlu, M. S. ve Öner, T. (2015). STEM eğitimi Türkiye raporu: Günün modası mı yoksa gereksinim mi?. İstanbul: Scala Basım Yayım.

Aydin Gunbatar, S., Tarkin-Celikkiran, A., Kutucu, E. S. \& Ekiz-Kiran, B. (2018). The influence of a design-based elective STEM course on pre-service chemistry teachers' content knowledge, 
STEM conceptions, and engineering views. Chemistry Education Research and Practice, 19(3), 954-972. doi:10.1039/C8RP00128F

Baran, E., Bilici, S. C., Mesutoglu, C. \& Ocak, C. (2016). Moving STEM beyond schools: Students' perceptions about an out-of-school STEM education program. International Journal of Education in Mathematics, Science and Technology, 4(1), 9-19. doi:10.18404/ijemst.71338

Berland, L. K. (2013). Designing for STEM integration. Journal of Pre-College Engineering Education Research (J-PEER), 3(1), 22-31. doi:10.7771/2157-9288.1078

Boesdorfer, S. \& Greenhalgh, S. (2014). Make room for engineering: Strategies to overcome anxieties about adding engineering to your curriculum. The Science Teacher, 81(9), 51-55.

Bybee, R. W. (2013). The case for STEM education: Challenges and opportunities. Arlington, VA: NSTA Press.

Capraro, R. M. \& Slough, S. W. (2008). Why PBL? Why STEM? Why now? An introduction to STEM project-based learning. In S. R. M. Capraro \& S. W. Slough (Eds.), Project-based learning: An integrated science, technology, engineering, and mathematics (STEM) approach (pp. 1-5). Rotterdam: Sense.

Cross, N. (2008). Engineering design methods: Strategies for product design (3rd ed.). Milton Keynes, UK: John Wiley \& Sons Inc.

Cunningham, C. M. \& Hester, K. (2007, March). Engineering is elementary: An engineering and technology curriculum for children. Paper presented at American Society for Engineering Education Annual Conference \& Exposition, Honolulu, HI.

Dym, C. L., Little, P., Orwin, E. J. \& Spjut, E. (2009). Engineering design: A project-based introduction (4th ed.). New York, NY: John Wiley \& Sons.

English, L. D. \& King, D. T. (2015). STEM learning through engineering design: Fourth-grade students' investigations in aerospace. International Journal of STEM Education, 2(1), 14. doi:10.1186/s40594-015-0027-7

Ercan, S. \& Şahin, F. (2015). Fen eğitiminde mühendislik uygulamalarının kullanımı: Tasarım temelli fen eğitiminin öğrencilerin akademik başarıları üzerine etkisi. Necatibey Eğitim Fakültesi Elektronik Fen ve Matematik Ë̆itimi Dergisi, 9(1), 128-164.

Estapa, A. T. \& Tank, K. M. (2017). Supporting integrated STEM in the elementary classroom: A Professional development approach centered on an engineering design challenge. International Journal of STEM education, 4(1), 6. doi:10.1186/s40594-017-0058-3

Evans, H. B. (1994). Water distribution in Ancient Rome: The evidence of frontinus. Michigan, MI: University of Michigan Press.

Flexner, S. B. (1987). The random house dictionary of the English language (2nd ed.). New York, NY: Random House.

Gencer, A. S., Doğan, H., Bilen, K. \& Can, B. (2019). Bütünleşik STEM eğitimi modelleri. Pamukkale Üniversitesi Eğitim Fakültesi Dergisi, 45, 38-55. doi:10.9779/PUJE.2018.221

Guzey, S. S., Moore, T. J. \& Harwell, M. (2016). Building up STEM: An Analysis of teacher-developed engineering design-based STEM integration curricular materials. Journal of Pre-College Engineering Education Research 6(1), 11-29. doi:10.7771/2157-9288.1129

Haik, Y. \& Shahin, T. (2011). Engineering design process (2nd ed.). Connecticut, CT: Cengage Learning.

Hill, D. R. (1996). A history of engineering in classical and medieval times. London: Routledge.

Honey, M., Pearson, G. \& Schweingruber, H. (2014). STEM integration in K-12 education: Status, prospects, and an agenda for research. Washington, DC: National Academies Press.

International Technology Education Association. (2000). Standards for technological literacy: Content for the study of technology. Reston, Va: ITEA.

Kelley, T. R. \& Knowles, J. G. (2016). A conceptual framework for integrated STEM education. International Journal of STEM Education, 3(1), 1-11. doi:10.1186/s40594-016-0046-Z

Langins, J. (2004). Conserving the enlightenment: French military engineering from vauban to the revolution. Cambridge: MIT Press.

Licker, D. M. (2003). Dictionary of engineering (2nd ed.). Chicago, IL: McGraw Hill.

Marulcu, İ. ve Sungur, K. (2012). Fen bilgisi öğretmen adaylarının mühendis ve mühendislik algılarının ve yöntem olarak mühendislik dizayna bakış açılarının incelenmesi. Afyon Kocatepe Üniversitesi Fen ve Mühendislik Bilimleri Dergisi, 12(1), 13-23. 
Mayer, R. E. (2010). Applying the science of learning. Upper Saddle River, NJ: Pearson.

Milli Eğitim Bakanlığı. (2016). STEM eğitimi raporu. Erişim adresi http://yegitek.meb.gov.tr/STEM_Egitimi_Raporu.pdf

Milli Eğitim Bakanlığı. (2018). Fen bilimleri dersi taslak öğretim programı(ilkokul ve ortaokul 3, 4, 5, 6, 7, 8. sinıflar). Ankara: Temel Eğitim Genel Müdürlügü.

Moon F. C. (2010). The influence of Archimedes in the machine books from the Renaissance to the 19th Century. In Paipetis S., \& Ceccarelli M. (Eds.), The genius of Archimedes: 23 centuries of influence on mathematics, science and engineering: Vol 11. Springer. doi:10.1007/978-90-4819091-1_30

Moore, T. J. \& Smith, K. A. (2014). Advancing the state of the art of STEM integration. Journal of STEM Education: Innovations and Research, 15(1), 5-10.

Morrison, J. (2006). TIES STEM education monograph series, attributes of STEM education. Baltimore, MD: TIES.

National Academies of Sciences, Engineering, and Medicine. (2020). Building capacity for teaching engineering in K-12 education. Washington, DC: National Academies Press.

National Academy of Engineering. (2004). The engineer of 2020: Visions of engineering in the new century. Washington, DC: National Academies Press.

National Aeronautics and Space Administration. (2011). Beginning engineering, science and technology educator guides: An educator's guide to the engineering design process grades 6-8. Retrieved from https://www.nasa.gov/pdf/630754main_NASAsBESTActivityGuide6-8.pdf

National Research Council. (2009). Engineering in K-12 education: Understanding the status and improving the prospects. Washington, DC: National Academies Press.

National Research Council. (2011). Successful K-12 STEM education: Identifying effective approaches in science, technology, engineering, and mathematics. Washington, DC: National Academy Press.

National Research Council. (2012a). Education for life and work: Developing transferable knowledge and skills in the 21st century. Washington, DC: National Academies Press.

National Research Council. (2012b). A Framework for K-12 science education: Practices, crosscutting concepts, and core ideas. Washington, DC: The National Academic Press.

National Research Council. (2013). Next generation science standards: For states, by states. Washington, DC: National Academies Press.

Özçelik, A. ve Akgündüz, D. (2018). Üstün/özel yetenekli öğrencilerle yapılan okul dışı STEM eğitiminin değerlendirilmesi. Trakya Üniversitesi Eğitim Fakültesi Dergisi, 8(2), 334-351.

Özkızılcık, M. ve Cebesoy, Ü. B. (2020). Tasarım temelli FeTeMM etkinliklerinin fen bilgisi öğretmen adaylarının problem çözme becerilerine ve FeTeMM öğretimi yönelimlerine etkisinin incelenmesi. Uludă̆ Üniversitesi Ĕgitim Fakültesi Dergisi, 33(1), 177-204.

Roehrig, G. H., Moore, T. J., Wang, H. H. \& Park, M. S. (2012). Is adding the E enough? Investigating the impact of K-12 engineering standards on the implementation of STEM integration. School Science and Mathematics, 112(1), 31-44. doi:10.1111/j.1949-8594.2011.00112.x

Simon, H. A. (1975). A Student's introduction to engineering design. New York, NY: Pergamon Press.

STEM Task Force Report. (2014). Innovate: A Blueprint for science, technology, engineering, and mathematics in California public education. Dublin, CA: Californians Dedicated to Education Foundation.

Şahin, E. \& Kabasakal, V. (2018). STEM eğitim yaklaşımında dinamik matematik programlarının (Geogebra) kullanımına yönelik öğrenci görüşlerinin incelenmesi. Anemon Muş Alparslan Üniversitesi Sosyal Bilimler Dergisi, 6(STEMES'18), 55-62. doi:10.18506/anemon.463877

TeachEngineering, (2020). Engineering design process. Retrieved from $\mathrm{https}: / / \mathrm{www}$. teachengineering.org/k12engineering/designprocess

Thomasian, J. (2011). Building a science, technology, engineering, and math education agenda: An Update of state actions. New York, NY: NGA Center for Best Practices.

Türk Sanayicileri ve İş İnsanları Derneği. (2014). STEM alanında eğitim almış işgücüne yönelik talep ve beklentiler araştırması. İstanbul: SIS Matbaacilık.

Uysal, E. ve Cebesoy, Ü. B. (2020). Tasarım temelli FeTeMM etkinliklerinin fen bilgisi ögretmen adaylarının bilimsel süreç becerilerine, tutumlarına ve bilgilerine etkisinin incelenmesi. SDU International Journal of Educational Studies, 7(1), 60-81. doi:10.33710/sduijes.614799 
Wang, H. H., Moore, T. J., Roehrig, G. H. \& Park, M. S. (2011). STEM integration: Teacher perceptions and practice. Journal of Pre-College Engineering Education Research, 1(2), 1-13. doi:10.5703/1288284314636

Yamak, H., Bulut, N. ve Dündar, S. (2014). 5. sınıf öğrencilerinin bilimsel süreç becerileri ile fene karş1 tutumlarına FeTeMM etkinliklerinin etkisi. Gazi Üniversitesi Gazi Eğitim Fakültesi Dergisi, 34(2), 249-265.

Yıldırım, B. ve Altun, Y. (2015). STEM eğitim ve mühendislik uygulamalarının fen bilgisi laboratuar dersindeki etkilerinin incelenmesi. El-Cezeri Journal of Science and Engineering, 2(2), 28-40.

\section{Extended Abstract}

\section{Introduction}

STEM disciplines are inseparable in the real world. Based on this idea, STEM education deals with the teaching of science, technology, engineering, and mathematics disciplines in an integrative way (STEM Task force Report, 2014). It is challenging for students to transfer separately acquired domain-specific concepts and skills to real-world problems and professional life (Honey, Pearson, and Schweingruber, 2014). This is an important issue, especially for a STEM-capable workforce. A STEM-capable workforce refers individuals who develop proficiency in 21st-century competencies such as cognitive (cognitive processes and strategies, knowledge, and creativity), intrapersonal (intellectual openness, work ethic and conscientiousness, and positive core self-evaluation), and interpersonal (teamwork and collaboration and leadership) domains (NRC, 2012a). The retention and transferability of the 21stcentury competencies are the ultimate goals for learning outcomes. An effective engineering integration in STEM education enables the acquisition of 21 st-century competencies in a meaningful way. The main problem faced at this point is how to achieve an effective engineering integration in STEM education. In this context, it is crucial to reveal the nature of engineering and examine how engineering can be integrated into STEM education.

Engineering includes four thousand years of experience and nearly two hundred years of scientific analysis, which provides an understanding of structural limits of matter (Hill, 1996). In the contemporary perspective, engineering has essential qualities. Thus, it is systematic, purposeful, iterative, embraces failure, depends on teamwork, inherently creative and optimistic, quintessentially human, and attentive to social and ethical concerns (NASEM, 2020; NRC, 2009). Engineering includes product or system design under certain constraints. The engineering design is accepted as a formal method of engineering (Haik and Shahin, 2011). The most accepted approach for the integration of engineering into STEM education is the transfer of engineering design to the teaching process. Engineering design is adapted to teaching processes by considering the dynamics of learning, such as required time, cognitive and psychomotor development levels of students, and the structure of the curriculum. Design processes (Cunningham and Hester, 2007; NASA, 2011; TeachEngineering, 2020), which are frequently used in engineering integration to STEM education, have a similar structure. In general, engineering design processes depend on teamwork and aim to solve a particular design problem. The required information is collected through research to solve the design problem. Different solutions are discussed based on the obtained evidence. The best solution, which meets the requirements and constraints, is selected among the discussed ideas. The sketches are drawn for the selected solution. Materials and methods are determined to fabricate the artifact. The prototype is built and tested. Improvements (revisions) are made until the product is qualified enough to meet the design requirements. Besides, the learning process should include essential engineering concepts, skills, and practices for effective engineering integration. These essential aspects are categorized as basic science and math concepts, domain-specific concepts, concepts common to most areas of engineering, engineering skills, and engineering practices (NRC, 2009, 2012a).

\section{Conclusions and Recommendations}

According to the results of the research, the following conclusions and recommendations can be stated: Using engineering design in the teaching process is the most common approach to integrate engineering into STEM education. It is crucial to involve essential engineering concepts, skills, (NRC, 2009) and practices (NRC, 2012b) to the teaching process in order to ensure high-quality integration. Engineeringbased activities that include solely engineering concepts and skills do not reflect the nature of STEM 
education. STEM education depends on the connection level between science, mathematics, engineering, and technology domain-specific/shared concepts and skills (Morrison, 2006). Mistakes in STEM education offer unique learning opportunities for students to shape their own learning. Instead of trying to correct these mistakes, STEM implementers should guide students to learn from them. Studies conducted in the context of Turkey (Aydin Gunbatar et al., 2018; Bozkurt Altan et al., 2018; Ercan and Sahin, 2015) show that integrating engineering in STEM education would be very beneficial in practice in accordance with the Turkish education system and culture.

${ }^{\mathrm{i}} \mathrm{Bu}$ makaleye birinci yazar \%60 ve ikinci yazar $\% 40$ oranında katkıda bulunmuştur. 